\title{
WEARABLE MASTER-SLAVE TRANING DEVICE FOR LOWER LIMB CONSTRUCTED WITH PNEUMATIC RUBBER ARTIFICIAL MUSCLES
}

\author{
Daisuke SASAKI*, Toshiro NORITSUGU* and Masahiro TAKAIWA* \\ ${ }^{*}$ Graduate School of Natural Science of Technology \\ Okayama University \\ 3-1-1 Tsushimanaka, Okayama, 700-8530 Japan \\ (E-mail:[daisuke, toshiro, takaiwa]@sys.okayama-u.ac.jp)
}

\begin{abstract}
The purpose of this study is to develop a wearable master-slave lower limb training device for a trainer and a trainee. The developed device is constructed with McKibben type rubber artificial muscles and an appliance, a torque sensor. In addition, to prevent applying an excessive torque to the trainee, a reaction torque from the trainee can be transmitted to the trainer by a bilateral type master-slave control system. In this paper, the structure of the developed device is discussed, and then the validity of the proposed device is evaluated from the experiments assumed a training.
\end{abstract}

\section{KEY WORDS}

Pneumatics, Artificial rubber muscle, Soft mechanism, Wearable robot

\section{INTRODUCTION}

Many kinds of power assist device have been developed to assist a hard work, rehabilitate a human body in recent years[1] - [5]. These devices are driven with various actuators such as a electric motor, a hydraulic cylinder and so on. Above all, a pneumatic artificial rubber muscle is effective to drive these device[4][5]. Since these devices used by a human is requried a safty and a light weight. This actuator has a mechanical flexibility by an air compressibility, a rubber material, and has a high power weight ratio. Therefore, this rubber muscle can realize a flexible and a light weight device by a simple mechanism.

The purpose of this study is to develop a masterslave lower limb training device for a trainer and a trainee. The developed master and the slave devices are constructed with McKibben type rubber artificial muscles and an appliance, a torque sensor. McKibben type rubber muscles are installed at the knee and the ankle joints of the appliance, respectively.

In this study, it is assumed that the master and the slave devices are used by the trainer and the trainee respectively, and that the trainer moves the trainee joint angles by moving the trainer's lower limb. To prevent applying an excessive torque to the trainee, a reaction torque from the trainee can be transmitted to the trainer by a bilateral type master-slave control system. In this paper, the structure of the develope$\mathrm{d}$ device is discussed, and then the validity of the proposed device is evaluated from the experiments assumed a training. 


\section{WEARABLE MASTER-SLAVE}

\section{TRANING DEVICE}

Figure 1, 2 show the structure and the overview of the developed device. McKibben type rubber muscles for a flexion and an extension are installed through a pulley to an appliance in the knee device. For example, when the flexion and the extension rubber muscles are increased and decreased the inner pressures from the balance states, the torque to flex the knee can be generated as shown in Figure 3(a). The extension torque can be also generated by decompressing and compressing the flexion and the extension rubber muscles. The weight is about $4.8[\mathrm{~kg}]$.

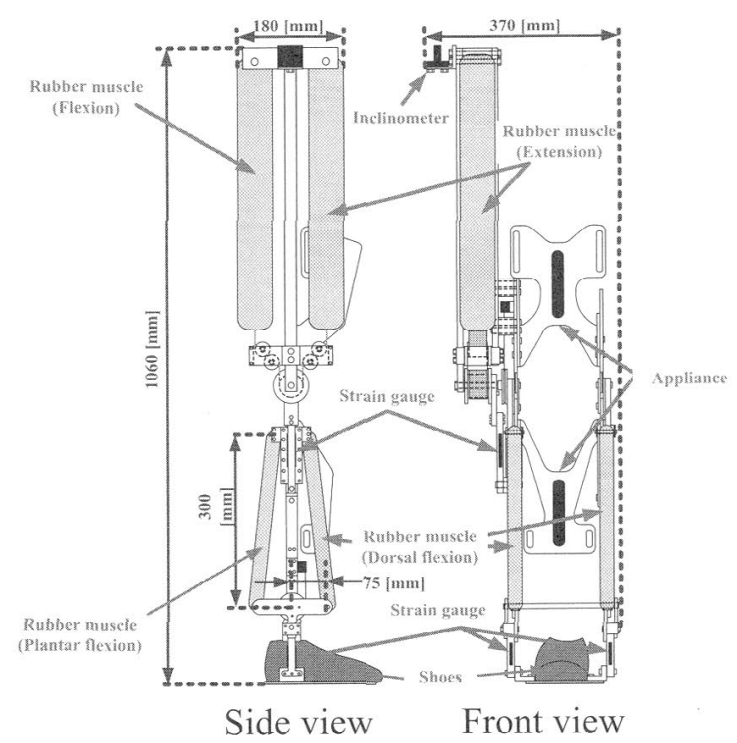

Figure 1 Structure of developed device

In the ankle device, rubber muscles for the dorsal and the plantar flexion are installed respectively. The dorsal and the plantar flexion mean the motions which bend and extend the ankle as shown in Figure 4. The movable angles at the knee and the ankle are limited from $0\left[^{\circ}\right]$ to $\left.1000^{\circ}\right]$ by the knee joint and from $-25\left[^{\circ}\right]$ to $25\left[^{\circ}\right]$ by the ankle rubber muscles. The generated torque from the rubber muscle is transmitted to the appliance through an aluminium plate, which is mounted a strain gauge. The generated torque can be detected from the strain of the aluminium plate.

McKibben type rubber muscle is constructed with the rubber tube. The rubber muscle is manufactured with a rubber tube and a polyester fiber tube. The fiber tube is the latticed tube weaved with a polyester

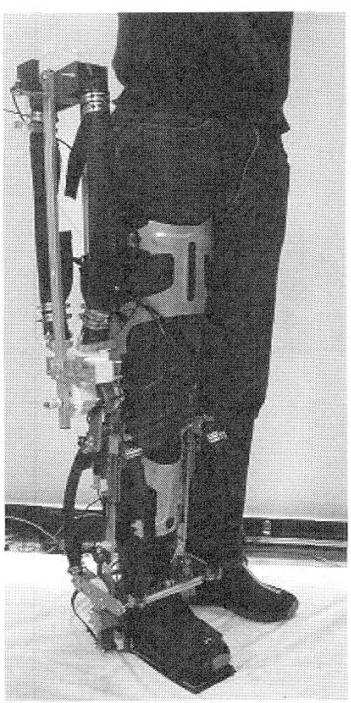

(a) Master device

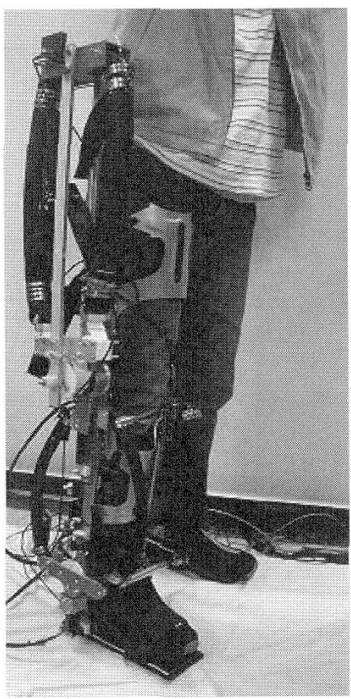

(b) Slave device
Figure 2 Overview of device

fiber. When a compressed air is supplied into the rubber tube, the rubber tube expands to the radial direction. The radial expansion force of the rubber tube is converted to the axial contraction force as shown in Figure 5.

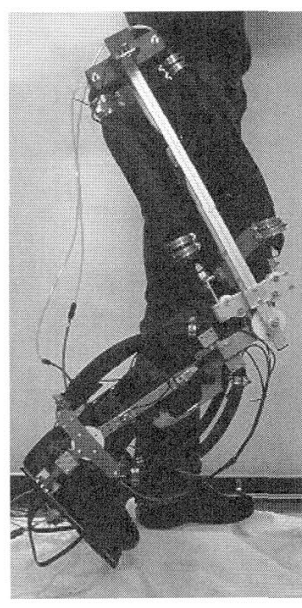

(a) Flexion

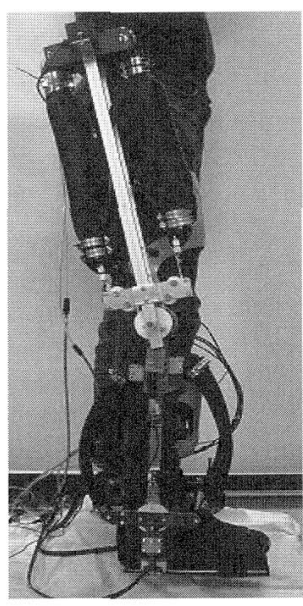

(b) Extension
Figure 3 Flexion and extension

In the knee device, the length and the outer and the inner diameter of the rubber tube are 396, 39.3, $30.0[\mathrm{~mm}]$, respectivcly. In the Ankle device, the length and the outer and the inner diameter of the rubber tube are $330,20.7,15.0[\mathrm{~mm}]$, respectively.

Figure 6 shows characteriscics of rubber muscle using the knee and ankle device. The rubber muscle is fixied with a force sensor and a sensor stage 
as shown in Figure 7, and the fixed distance $L_{m}$ is changed in order to measure the force at the each contraction length of rubber muscle. In the expriment, the generated force is measured at the each contraction length in a constant supplied pressure.

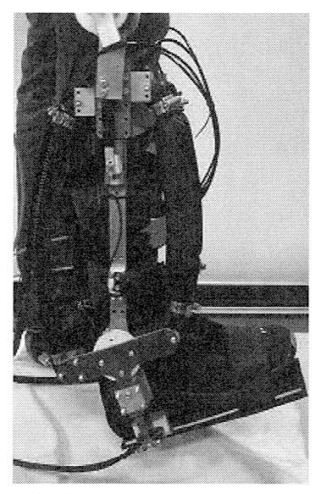

(a) Dorsal flexion

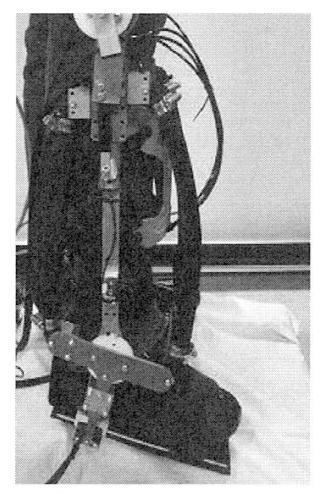

(b) Plantar flexion
Figure 4 Dorsal and plantar flexion

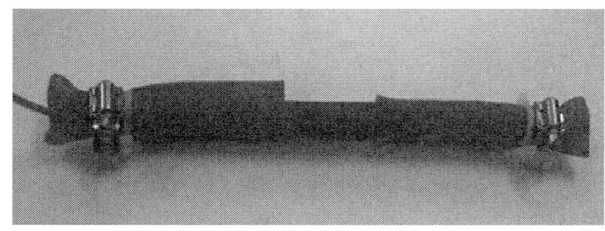

(a) Initial state

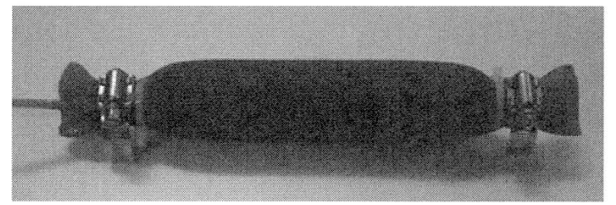

(b) Pressurized state

Figure 5 Overview of rubber muscle

From the force characteristics, the diameter of pulley at the knee is $40[\mathrm{~mm}]$, and the ankle rubber muscle is fixed at the distance $75[\mathrm{~mm}]$ from the ankle joint.

Figure 8, 9 show torque characteristics of master device. The joint angle of knee and ankle are defined as shown in Figure 10. In the figure, subscript $m$ and $s$ represent the master and slave device, and $k$ and $a$ represent the knee and ankle device, respectively. The flexion angle from the standing state is defined as a plus in the knee angles $\left(\theta_{k m}, \theta_{k s}\right)$, and the dorsal flexion angle is also defined as a plus in the ankle ones $\left(\theta_{a m}, \theta_{a s}\right)$. These characteristics in Figure 8,9 are measured to verify the influence of the angle upon the torque. In the walking motion, the maximum flexion and extension torques at the knee are about $35,-60[\mathrm{Nm}]$, respectivery. In addition, the maximum dorsal, plantar flexion ones at the ankle are about $10,-120[\mathrm{Nm}]$, respectivery[1]. From the above, this device can assist about 50[\%] at the lowest at $T_{e m k}$ of the working torque even when the user decreases the muscular power.

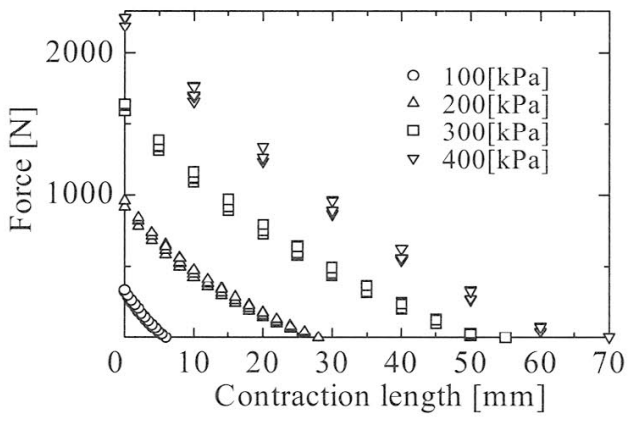

(a) For knee device

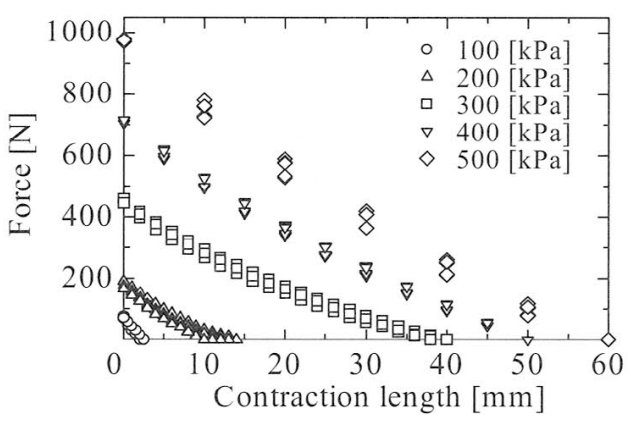

(b) For ankle device

Figure 6 Force characteristics of rubber muscle

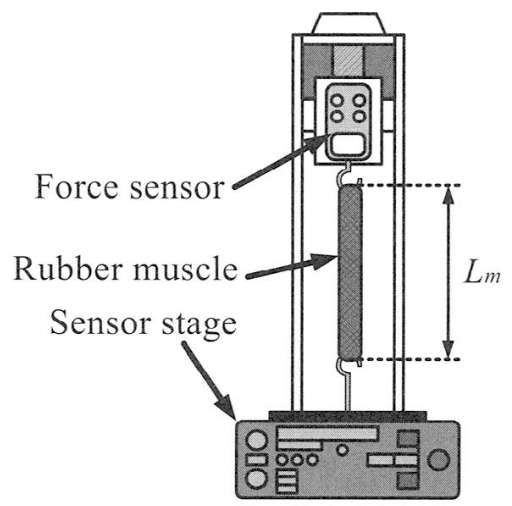

Figure 7 Experimental device

\section{CONTROL SYSTEM}

Figure 11 shows a constructed control system, 


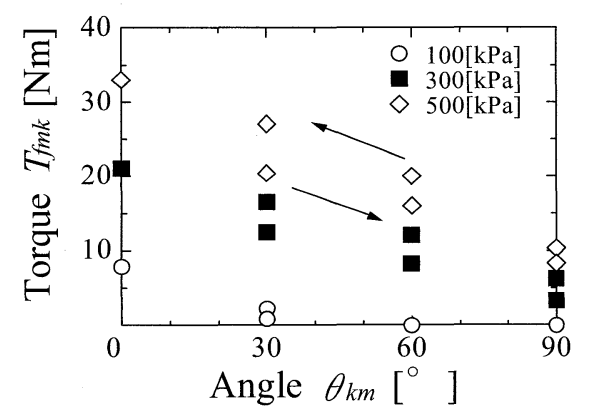

(a) Flexion

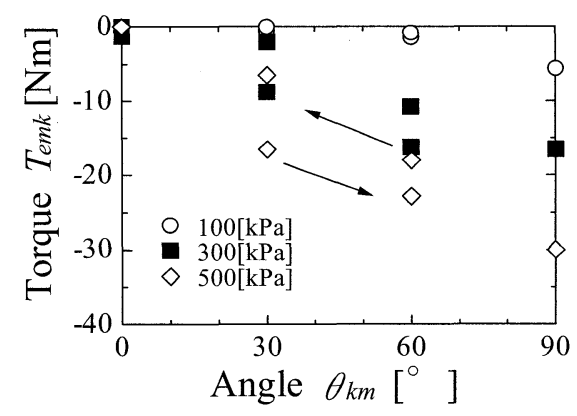

(b) Extension

Figure 8 Torque of knee device (master)

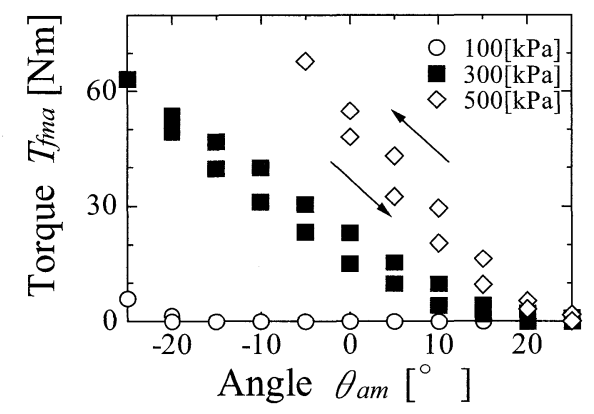

(a) Dorsal flexion

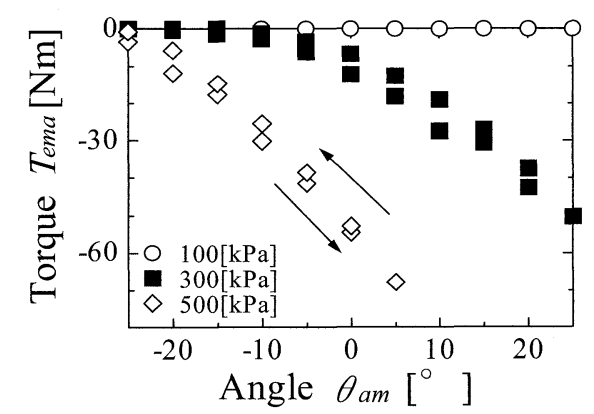

(b) Plantar flexion

Figure 9 Torque of ankle device (master) which is a force feedback master-slave system to feedback a slave reaction torque to a master user. The main system parameters used in this system are shown in Table 1. The torque and the angle control systems are constructed in the master and the slave devices, respectively. The reference angle in the slave control system is the master measured angle $\boldsymbol{\theta}_{m}\left(=\left[\theta_{m k}\right.\right.$, $\left.\theta_{m a}\right]^{T}$ ), and the torque control system is inputted the slave reaction torque $\boldsymbol{T}_{s}\left(=\left[T_{s k}, T_{s a}\right]^{T}\right)$, which is obtained by deducting $\boldsymbol{T}_{w s}$ from $\boldsymbol{T}_{M s}$ and by multiplying a gain $\boldsymbol{K}$.

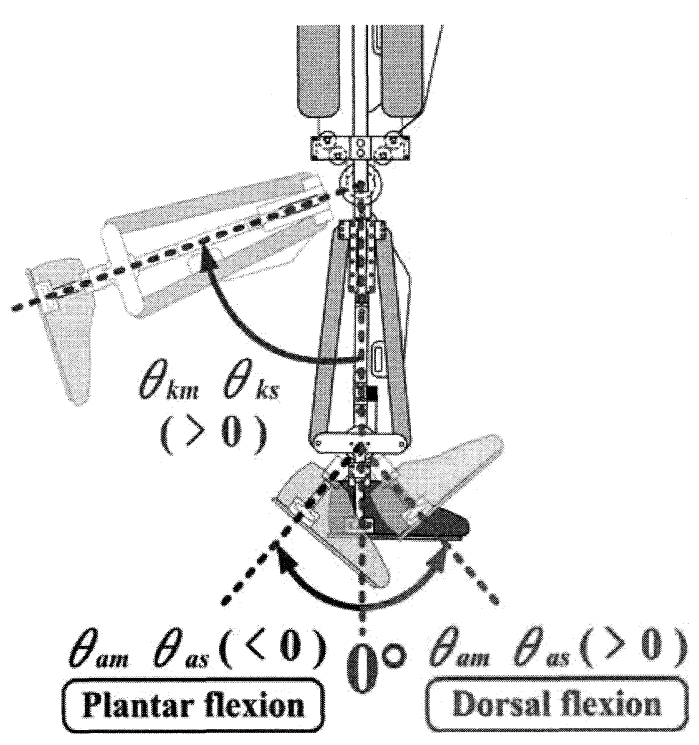

Figure 10 Angle definition

The gain $\boldsymbol{K}$ is introduced in order to generate the master torque in the opposite direction against the slave reaction torque, because the master device must generate the slave reaction torque applied to the slave device by the slave user. $\boldsymbol{K}$ is as follows:

$$
\boldsymbol{K}=\begin{array}{cc}
-1 & 0 \\
0 & -1
\end{array}
$$

In this system, the antagonisitic rubber muscles, the flexion and the extension ones at the knee device e.g., are compressed / decompressed from the balance pressure, the flexion and the extension torque $\boldsymbol{T}_{M m}, \boldsymbol{T}_{M s}$ can be applied to the appliance.

\section{EXPERIMENT}

A preriodical step motion assumed a wolk training is experimented in order to verify the proposed device. In this experiment, the slave user is restricted the flexion and the dorsal flexion by a nylon belts as 


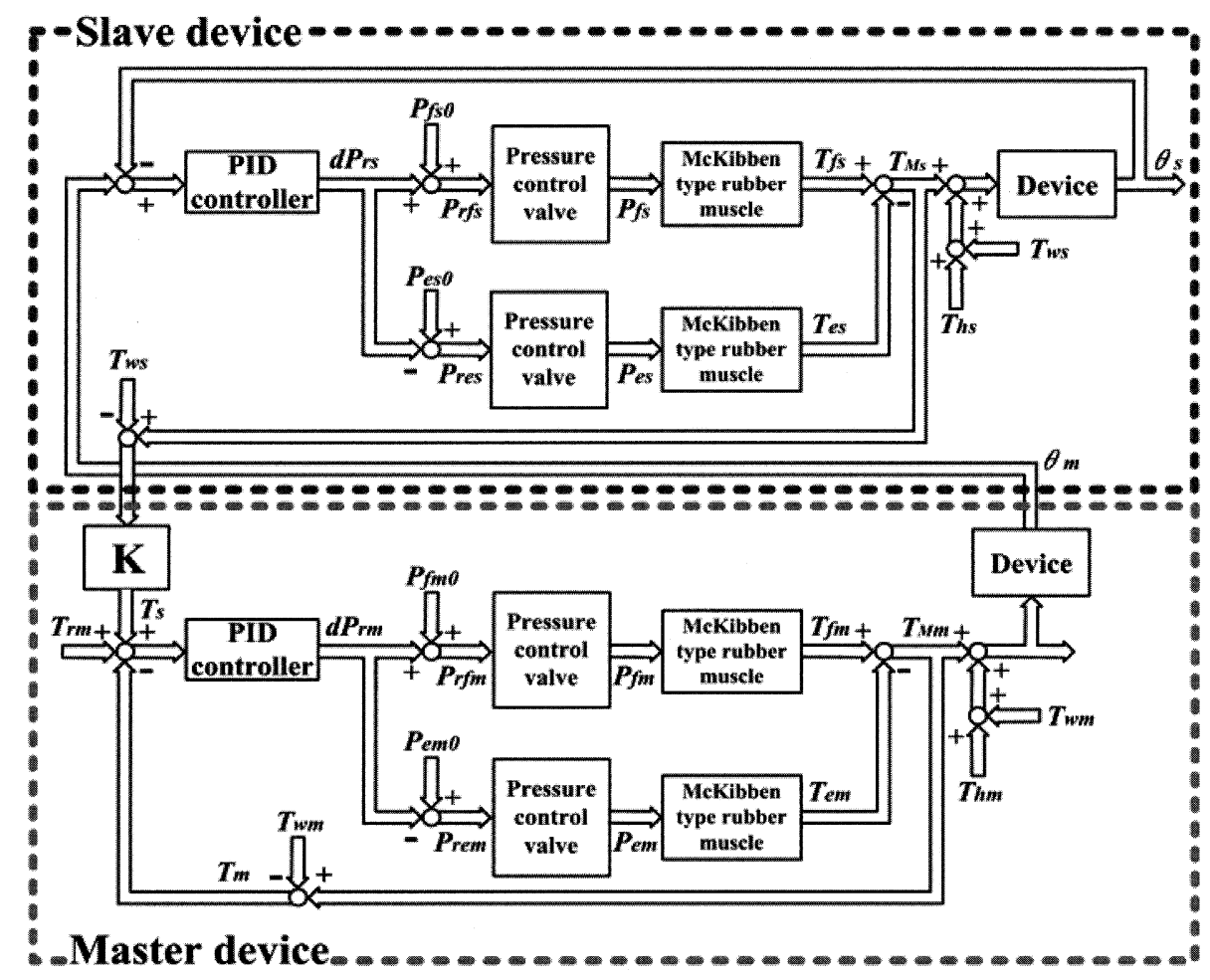

Figure 11 Control system

Table 1 System parameters

\begin{tabular}{|c|c|c|}
\hline \multicolumn{3}{|c|}{ Master } \\
\hline $\boldsymbol{\theta}_{m}$ & Joint angle & {$[\mathrm{rad}]$} \\
\hline$T_{M m}$ & Applied torque & {$[\mathrm{Nm}]$} \\
\hline$T_{h m}$ & Human torque & {$[\mathrm{Nm}]$} \\
\hline$\overline{\boldsymbol{T}_{w m}}$ & Weight torque & {$[\mathrm{Nm}]$} \\
\hline $\boldsymbol{P}_{r f m}$ & $\begin{array}{c}\text { Reference pressure } \\
\text { Knee:flexion } \\
\text { Ankle:dosal flexion }\end{array}$ & {$[\mathrm{kPa}]$} \\
\hline $\boldsymbol{P}_{\text {rem }}$ & $\begin{array}{l}\text { Reference pressure } \\
\text { Knee:extension } \\
\text { Ankle:plantar flexion }\end{array}$ & {$[\mathrm{kPa}]$} \\
\hline $\boldsymbol{P}_{f m}, \boldsymbol{P}_{e m}$ & Measured pressure & {$[\mathrm{kPa}]$} \\
\hline \multicolumn{3}{|c|}{ Slave } \\
\hline $\boldsymbol{\theta}_{s}$ & Joint angle & [rad] \\
\hline $\boldsymbol{T}_{M s}$ & Applied torque & {$[\mathrm{Nm}]$} \\
\hline$T_{h s}$ & Human torque & {$[\mathrm{Nm}]$} \\
\hline $\boldsymbol{T}_{w s}$ & Weight torque & {$[\mathrm{Nm}]$} \\
\hline $\boldsymbol{P}_{r f s}, \boldsymbol{P}_{r e m}$ & Reference pressure & {$[\mathrm{kPa}]$} \\
\hline $\boldsymbol{P}_{f m}, \boldsymbol{P}_{e m}$ & Measured pressure & {$[\mathrm{kPa}]$} \\
\hline
\end{tabular}

shown in Figure 12, and the master user periodically steps on the right leg. Nylon belts reproduce contractures on the slave user. The slave user does not apply the torque with the leg, and the master user moves as follows:

$$
0 \sim 5[\mathrm{~s}]
$$

The master user flexes the knee, and the ankle to the dorsal direction from the standing state.

$$
5 \sim 10[\mathrm{~s}]
$$

The master user keeps the angles.

$10 \sim 15[\mathrm{~s}]$

The master user extends the knee, and flexes the ankle until the standing state.

$15 \sim 20[\mathrm{~s}]$

The master user keeps the angles.

$20 \sim 40[\mathrm{~s}]$

The master user repeats the above movements.

Figure 13, 14, 15, 16 show the experimental results. Figure 13, 15 show the results without the nylon belts, and Figure 14, 16 show the results with the nylon belts. The angle is decreased and the torque is increased on the knee as compared with the results 


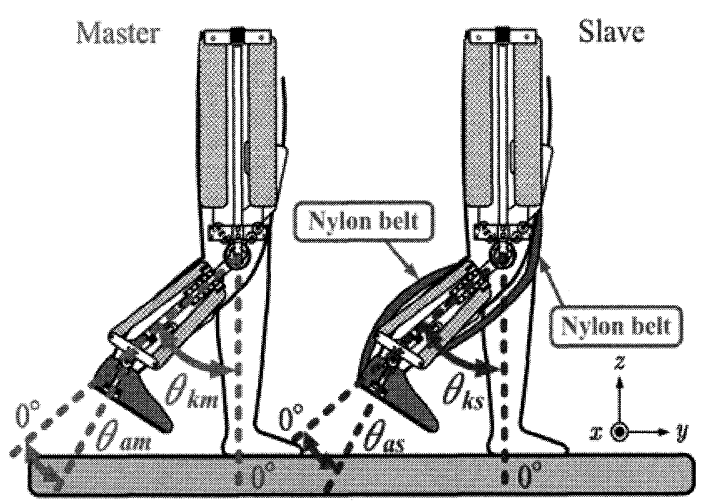

Figure 12 Experimental condition

without the restriction. On the ankle, the torque is also increased as compared with the results without the restriction.

From the above results, the joints stiffnesses of the slave user can be transmitted to the master user even when the joints stiffnesses is increased by the restriction. Because the torque at the knee with the joint restriction is bigger than the torque without the restriction even then the knee angle with the restriction is smaller than the angle without the restriction. In addition, the torque at the ankle with the joint restriction is also bigger than the torque without the restriction.

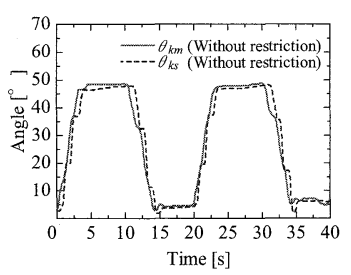

(a)Angle

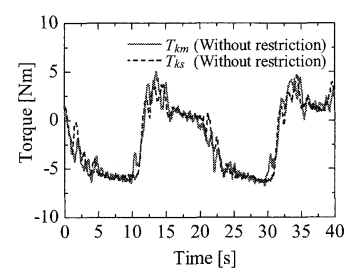

(b)Torque
Figure 13 Without restriction (knee)

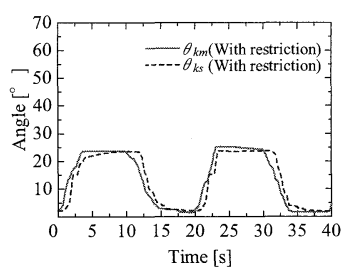

(a)Angle

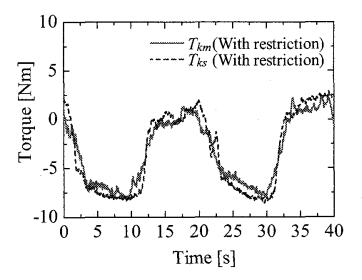

(b) Torque
Figure 14 With restriction (knee)

\section{CONCLUSION}

In this study, the wearable master-slave lower limb training device which can be used by a trainer and a trainee has been developed. In this paper, the struc-

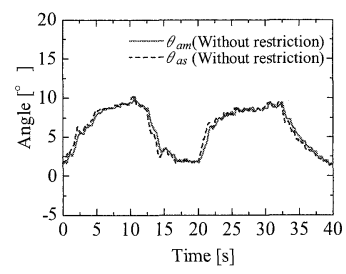

(a)Angle

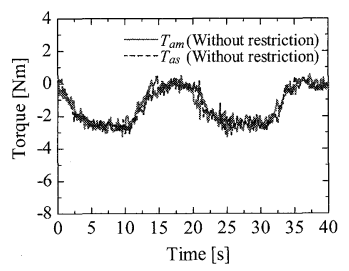

(b) Torque
Figure 15 Without restriction (ankle)

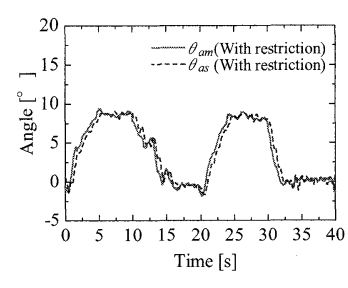

(a)Angle

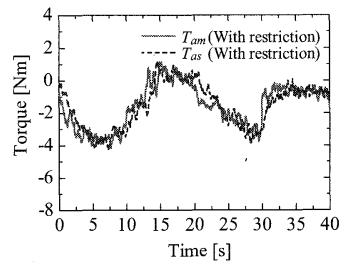

(b)Torque
Figure 16 With restriction (ankle)

ture of the developed device has been discussed, and then the validity of the proposed device is evaluated from the experiments assumed the step motion.

From the results, the joints stiffnesses of the slave user increased by the restrictions can be transmitted to the master user by the proposed device.

\section{REFERENCES}

1. A.Chu, H.Kazerooni, A.Zoss:

"On the Biomimetic Design of the Berkeley Lower Extremity Exoskeleton(BLEEX)", Proc. of the 2005 IEEE International Conference on Robotics and Automation (DVD-ROM), pp.4356-4363, 2005.

2. Y.Mori, K.Takayama, T.Zengo, T.Nakamura: "Development of Straight Style Transfer Equipment for Lower Limbs Disabled: Verification of Basic Motion", Journal of Robotics and Mechatronics, Vol.16, No.5, pp.456-463, 2004.

3. J. Nikitczuk, B. Weinberg, C. Mavroidis: "Rehabilitative Knee Orthosis Driven by ElectroRheological Fluid Based Actuators", Proc. of the 2005 IEEE International Conference on Robotics and Automation (DVD-ROM), pp.2294-2300, 2005.

4. D.Sasaki, T.Noritsugu, M.Takaiwa: "Development of Pneumatic Power Assist Sprint "ASSIST" Operated by Human Intention", Journal of Robotics and Mechatronics, Vol.17, No.5, pp.568-574, 2005.

5. H.Kobayashi, T.Siiba, Y.Ishida: "Realization of All 7 Motions for the Upper Limb by a Muscle Suit", Journal of Robotics and Mechatronics, Vol.16, No.5, pp.504-512, 2004. 